\title{
The Balance Improvement of Final Assembly Water Pump Business Unit Tracks Section : Case Study
}

\author{
Ikhsan Siregar ${ }^{*}$, Gretty Margaretha ${ }^{1}$, Tigor Hamonangan Nasution ${ }^{2}$ and Ulfi Andayani ${ }^{3}$ \\ ${ }^{1}$ Department of Industrial Engineering, Faculty of Engineering, University of Sumatera Utara, \\ Almamater Rd., Medan 20155, Indonesia. \\ 2 Department of Electrical Engineering, Faculty of Engineering, University of Sumatera Utara, \\ Almamater Rd., Medan 20155, Indonesia. \\ ${ }^{3}$ Department of Information Technology, Faculty of Engineering, University of Sumatera Utara, \\ Almamater Rd., Medan 20155, Indonesia.
}

\begin{abstract}
This research was conducted at an electronic field assembly company. The company implements a production system that starts from semi-finished goods to finished products. The problem of the company is the imbalance of the production trajectory. The track balance in the final assembly will affect the amount of product that can be produced. The unbalanced track conditions resulted a bottleneck condition in the material flow from one work center to the other, resulting in delay time on the production floor. The problems are caused by large cycle times, thus resulting in different production capacities for each workcenter. The implementation of the theory of constraints is to identify the existing constraints and to obtain the optimum amount of workcenter as well as to allocate elements of activity in the workcenter, thereby improving the efficiency of the production line.. In actual trajectory there are 7 work centers with track path efficiency $59,80 \%$, balance delay $40,20 \%$, and smoothing index 74,47 . The result of balancing in the production line using theory of constraint method obtained the repair solution by number of work center as many as 5 work centers with track efficiency value $88,65 \%$, balance delay $11,35 \%$ and smoothing index 17,07 .
\end{abstract}

\section{Introduction}

The balance of the production process assembly line in the mass manufacturing industry is an important part of the production process. This is related to the existence of several jobs that are grouped in several WC (work center). The operator's ability to do assembly activities will affect the number of products in each process. The assembly time of each work element is determined by the length of time required in the assembly. Track balance in the assembly process will affect the achievement of production targets. Unfulfilled production targets will cause losses for the company.

\footnotetext{
*Corresponding author: ikhsan.siregar@usu.ac.id
} 
Previous research has suggested that line balancing issues to determine the optimal allocation of assembly operations to a set of workstations, with related constraints and choose which precedence. This study based on case study that is ultimately discussed to demonstrate the capabilities of the proposed method in finding the optimal solution [1] . Another research on line balancing suggests that multi-objective hybrid optimization algorithms aimed at simultaneously resolving line balancing, equipment and buffer selection, measuring problems with capacity-oriented capacity and objectives, in other words looking to optimize in the production path [2]

Research for line balancing is widely applied to the manufacturing industry as in research conducted on the world of airplanes [3]. In other hand, there was also a line balancing study conducted in the automotive industry such as done in the europe automotive industry [4]. Line balancing is very influential on workers, such as previous research that discusses the Heuristic Algorithm associated with the assignor to the worker [5]. The purpose of line balancing is clear, ie optimizing production and looking for better benefits than before as in the research conducted about the production line with maximal stretch and get the optimal profit [6].

Previous research has also been studied with many methods similar to this research method, namely the Theory of Constraint (TOC) method. In a previous study it was mentioned that analyzing whether the Theory of Constraints (TOC) could be beneficial to hospital record logistics, the study proves that this method can be applied anywhere [7]. In another study stated that the method is also very good in its use in project management, where the study discusses the system of supervision and monitoring in project management [8]. Some even apply to the furniture industry to look for optimal products [9]. This method is categorized in the category of artificial intelligence, where the artificial intelligence is much studied by the field of Computer Science before, but has now been applied in all fields such as application on the production of light bulbs [10]. Another study of artificial intelligence is the comparison of the theory of forecasting in sood production [11].

Trajectory imbalances are also experienced at the site of this research, where the company where the research is conducted is engaged in electronics and is a manufacturing company. One of the company's results is a water pump. The initial naming done to the assembly of the company in the water pump product is symbolized by $\mathrm{X}$, where the constraints are due to the presence of idle operators, another constraint is to wait for the material to be processed. The difference in production speed between the workcenter causes an imbalance in the production line and the production target is not achieved. Thus it can be concluded that the problem is caused by the allocation of work elements are not balanced and cause congestion. This can be overcome by using Theory of Constraints (ToC) method. This study is limited by not taking into account the cost of losses due to imbalances that occur and does not analyze the achievement of production targets.

\section{Research Method}

\subsection{The Aim of This Study}

The general purpose of this study is to obtain improved production lines through a more efficient equilibrium with Theory of Constraint (TOC) method so as to facilitate the flow of production and production targets achieved, to identify bottleneck work centers, to allocate elements of activity, and to compare initial track conditions with proposed trajectories better. 


\subsection{Data Processing Method}

The steps in the process of data processing are:

A. Identify a System Constraint

B. Calculate the standart time of the final assembly process

C. of the five steps of the theory of constraint

a. Identify system constraints with CRT (Current Reality Tree)

b. Determine how to know the constraints with Identify the workstation bottleneck with CRD (Conflict Resolution Diagram) and Calculation of time required and available time

c. Repairs with Line Balancing Solutions to Reduce Constraints. Determination of the best solution based on Line balancing criteria, namely Line efficiency, Balance Delay, and Smoothing Index.

Trajectory efficiency

$$
\begin{array}{r}
\mathrm{E}=\frac{\text { Tproduct }}{\text { Tmax X WC }} \times 100 \% \\
\mathrm{D}=\frac{\mathrm{nSm}-\Sigma \mathrm{Si} \text { Bance Delay }}{(\mathrm{n})(\mathrm{Sm})} \times 100 \% \ldots
\end{array}
$$

Smoothing Index

$$
\mathrm{SI}=\sqrt{\sum_{i=1}^{\mathrm{K}}\left(\mathrm{STi} \mathrm{max}_{\max }-\mathrm{STi}\right)^{2}}
$$

\section{Results and Discussion}

\subsection{Application of Theory of Constraints on Final Assembly Process}

The theoretical steps of constraints consist of five steps:

\section{Identify a System Constraint}

This stage requires observation of the problem on the final assembly process to be solved. This requires cause-and-effect to identify the basic causes of the imbalance of the assembly line path to the core problem. Based on the observations that have been done, then the equilibrium of the path that has been found is arranged in the form of the current reality tree diagram (CRT) to see the causal relationship. Figure diagram of CRT can be seen in Figure 1.

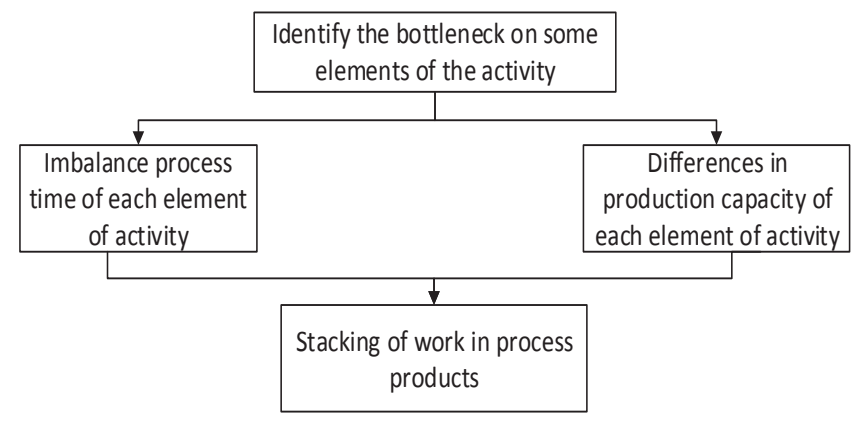




\section{Figure 1. Current Reality Tree (CRT)}

Figure 1 explains the main cause of track balance problem and the conclusion that can be drawn from the CRT diagram that the main factor causing constraints on the final assembly process in the company during the research is the existence of bottlenecks.

\section{Exploit Existing Obstacles}

This second phase aims to build a simple and practical solution to overcome bottleneck constraints on the final assembly process of the CRT diagram. If the CRT sought is the main cause of the problem, then in the constraint exploitation phase used the Conflict Resolution Diagram (CRD) tool which prioritized the goal, ie reducing or eliminating the bottleneck and seeing the conflicts arising from the various solutions. The solution focuses on the cause of the path prose imbalance in the final prose assembly with respect to processing time. The CRD image can be seen in Figure 2.

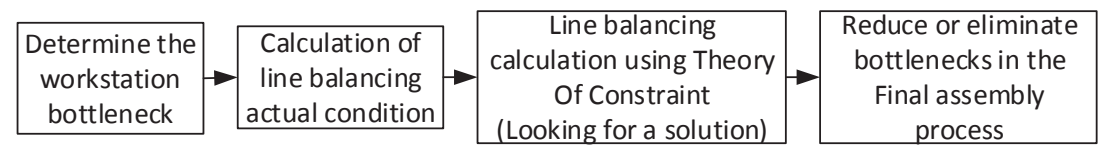

Figure 2. Conflict Resolution Diagram

Figure 2 describes the steps that must be done in solving the path equilibrium problem. Once the solution is determined to overcome the existing constraints by using CRD, then the next stage is to deploy solutions to the Work center bottleneck.

Bottleneck occurs when the time required is greater than the time available in the sense that the work centre cannot produce in accordance with predetermined production targets and consequently the existence of raw materials that accumulate. Work center bottleneck can be seen in Table 1.

From Table 1 can be seen there are three elements of work that experience the bottleneck of the work elements of checking pumps and water remover and attachment of barcodes, warranty paper, and manuals (work elements 16 and 17). From the results of this calculation clearly shows that the existence of bottleneck constraints and the imbalance of production time of each work element.

Table 1. Bottleneck Working Element on Final Assembly Process

\begin{tabular}{|c|r|r|r|}
\hline $\begin{array}{c}\text { Working } \\
\text { Element }\end{array}$ & $\begin{array}{c}\text { Time Available } \\
\text { (sec) }\end{array}$ & $\begin{array}{c}\text { Time Taken } \\
\text { (sec) }\end{array}$ & $\begin{array}{c}\text { Difference } \\
\text { (sec) }\end{array}$ \\
\hline 1 & 5748,91 & 5607,54 & 141,37 \\
\hline 2 & 7724,38 & 7534,44 & 189,94 \\
\hline 3 & 4365,57 & 4258,22 & 107,35 \\
\hline 4 & 5678,42 & 5538,79 & 139,63 \\
\hline 5 & 3684,67 & 3594,07 & 90,61 \\
\hline 6 & 14646,03 & 14165,84 & 480,20 \\
\hline 7 & 4571,65 & 4421,76 & 149,89 \\
\hline 8 & 16115,92 & 15851,72 & 264,20 \\
\hline 9 & 5553,74 & 5462,70 & 91,04 \\
\hline 10 & 6586,64 & 6478,67 & 107,98 \\
\hline 11 & 15801,84 & 15542,79 & 259,05 \\
\hline 12 & 5856,00 & 5760,00 & 96,00 \\
\hline
\end{tabular}




\begin{tabular}{|r|r|r|r|}
\hline 13 & 17083,43 & 16943,40 & 140,03 \\
\hline 14 & 7836,10 & 7771,87 & 64,23 \\
\hline 15 & 8217,87 & 8150,51 & 67,36 \\
\hline 16 & 39837,69 & 40164,23 & $-326,54$ \\
\hline 17 & 6919,81 & 6976,53 & $-56,72$ \\
\hline 18 & 14105,19 & 13989,57 & 115,62 \\
\hline 19 & 3799,43 & 3768,29 & 31,14 \\
\hline 20 & 6586,64 & 6532,66 & 53,99 \\
\hline 21 & 3310,45 & 3283,31 & 27,13 \\
\hline
\end{tabular}

3. Repairs with Line Balancing Solutions to Reduce Constraints

The track balancing steps can be seen as follows.

a. Actual Condition

Shows the actual condition of the company according to the precedence sequence diagram. Based on precedence diagrams that have been sorted can be seen idle time each work center that can be seen in Table 2 .

Table 2. Task Determination of Each Work Station According to the Actual Condition

\begin{tabular}{|c|c|c|c|c|}
\hline $\begin{array}{c}\text { Work } \\
\text { Center }\end{array}$ & Working Element & $\begin{array}{c}\text { Standard Time } \\
\text { (second) }\end{array}$ & $\begin{array}{c}\text { Cycle Time } \\
\text { (second) }\end{array}$ & $\begin{array}{c}\text { Idle } \\
\text { (second) }\end{array}$ \\
\hline I & 1 & 6.98 & 40.28 & 19.50 \\
\hline & 2 & 11.80 & & \\
\hline & 3 & 7.16 & & \\
\hline & 4 & 8.43 & 19.33 & 40.44 \\
\hline II & 5 & 5.91 & & 24.83 \\
\hline & 6 & 11.84 & 34.95 & \\
\hline III & 7 & 7.49 & & 34.34 \\
\hline & 8 & 15.05 & 25.44 & \\
\hline & 9 & 9.10 & & 19.75 \\
\hline IV & 10 & 10.80 & 40.02 & \\
\hline & 11 & 15.50 & & \\
\hline V & 12 & 9.93 & & \\
\hline & 13 & 13.71 & & \\
\hline & 14 & 12.85 & & \\
\hline VI & 15 & 13.47 & 39.78 & \\
\hline & 16 & 49.76 & & \\
\hline VII & 17 & 10.01 & & 163.80 \\
\hline & 18 & 13.12 & & \\
\hline & 19 & 6.43 & & \\
\hline & 20 & 10.23 & & \\
\hline & 21 & 5.04 & & \\
\hline
\end{tabular}

Trajectory efficiency

$$
\mathrm{E}=\frac{258.08}{7 \times 61,65} \times 100 \%=59,80 \%
$$

Balance Delay

$$
\mathrm{D}=\frac{7 \times 61,65-\sum 258.08}{7 \times 61,65} \times 100 \%=40,20 \%
$$

Smoothing Index

$$
\mathrm{SI}=\sqrt{\left(41,29^{2}\right)+\left(19,20^{2}\right)+\ldots .+(35,58)^{2}} \text {. }
$$




$$
=59,80
$$

The solutions in Table 2 are based on actual conditions. The approach solution is determined based on the number of workcenter, number of work elements on each workcenter, and the standard time of each work center. Iteration 0 is done by following the number of workcenter from initial that is as much as 6 workcenter, and work element is sorted according to actual situation at company. The optimal number of workcenter can be searched by using the following formula.

$$
W C=\frac{T_{\text {product }}}{\operatorname{Tmax}}=\frac{258,08}{50,31}=5,13 \approx 5
$$

So on the iteration done the number of workcenter reduction one by one approaching the optimal number of workcenter. At 0 iteration, the division of work elements in each work center is done by trial and error which can be seen in Table 3 .

\begin{tabular}{|c|c|c|c|c|}
\hline $\begin{array}{l}\text { Work } \\
\text { Center }\end{array}$ & $\begin{array}{l}\text { Working } \\
\text { Element }\end{array}$ & $\begin{array}{l}\text { Standart } \\
\text { Time } \\
\text { (second) }\end{array}$ & $\begin{array}{c}\text { Cycle } \\
\text { Time } \\
\text { (second) }\end{array}$ & $\begin{array}{c}\text { Idle } \\
\text { (second) }\end{array}$ \\
\hline \multirow[t]{5}{*}{ I } & 1 & 6,12 & 41,29 & 9,01 \\
\hline & 2 & 12,66 & & \\
\hline & 3 & 7,16 & & \\
\hline & 4 & 9,31 & & \\
\hline & 5 & 6,04 & & \\
\hline \multirow[t]{4}{*}{ II } & 6 & 11,71 & 43,63 & 6,68 \\
\hline & 7 & 7,49 & & \\
\hline & 8 & 15,32 & & \\
\hline & 9 & 9,10 & & \\
\hline \multirow[t]{3}{*}{ III } & 10 & 10,80 & 35,90 & 14,41 \\
\hline & 11 & 15,50 & & \\
\hline & 12 & 9,60 & & \\
\hline \multirow[t]{3}{*}{ IV } & 13 & 13,71 & 40,02 & 10,28 \\
\hline & 14 & 12,85 & & \\
\hline & 15 & 13,47 & & \\
\hline $\mathrm{V}$ & 16 & 50,31 & 50,31 & 0,00 \\
\hline \multirow[t]{6}{*}{ VI } & 17 & 11,34 & 46,92 & 3,39 \\
\hline & 18 & 13,12 & & \\
\hline & 19 & 6,23 & & \\
\hline & 20 & 10,80 & & \\
\hline & 21 & 5,43 & & \\
\hline & & TOTAL & & 43,77 \\
\hline
\end{tabular}

Table 3. Zero Iteration of Final Assembly Process

Trajectory efficiency

Balance Delay

$$
\mathrm{E} \quad=\frac{258,08}{6 \times 50,31} \times 100 \%=85,28 \%
$$

$$
\mathrm{D}=\frac{6 \times 50,31-\sum 258,0 \varepsilon}{6 \times 50,31} \times 100 \%=14,50 \%
$$


Smoothing Index

$$
\begin{aligned}
\mathrm{SI} & =\sqrt{(9,01)^{2}+(6,68)^{2}+\ldots .+(3,39)^{2}} \\
& =15,59
\end{aligned}
$$

In Table 3. which is the 0 iteration steps, it occurs that the number of work elements in WC II-WC V. Items affects the value of track balance criteria. Better track efficiency is available than actual condition, and smoothing index is smaller than actual $(15.59<59,80)$. Therefore iterated back. The next iteration is done by subtracting $1^{\text {st }}$ work center, and rebalancing the trajectory by trial and error ie replacing all working elements on the WC contained in iteration 0 . The result of $1^{\text {st }}$ iteration can be seen in the following calculation.

Trajectory efficiency

$$
E=\frac{258,08}{5 \times 58,22} \times 100 \%=88,65 \%
$$

Balance Delay

Smoothing Index

$$
D=\frac{5 \times 58,22-\sum 258,0 \varepsilon}{5 \times 58,22} \times 100 \%=11,35 \%
$$

$$
\begin{aligned}
\mathrm{SI} & =\sqrt{(5,22)^{2}+(0,00)^{2}+\ldots .+(11,30)^{2}} \\
& =31,48
\end{aligned}
$$

In the $1^{\text {st }}$ iteration the path's efficiency is higher than 0 iteration $\left(1^{\text {st }}\right.$ iteration $>$ Iteration $0=88,65>85,50$ ) and the optimal number of work center has been reached that is 5 work center. Re-do trial and error to see if the track efficiency value will be better if the work center is reduced once again to 4 . Thus, the method on iteration 1 can be continued to iteration 2. The iteration is done until it is filled with the stop rule ie the amount of idle time increases and Reduced efficiency at iteration 2, Working elements modified at all work centers by trial and error. Here are the calculations:

Trajectory efficiency

$$
E=\frac{258,08}{4 \times 76,63}=84,20 \%
$$

Balance Delay

Smoothing Index

$$
D=\frac{4 \times 76,63-\sum 258,08}{4 \times 76,63} \times 100 \%=15,80 \%
$$

$$
\begin{aligned}
\mathrm{SI} & =\sqrt{(16,13)^{2}+(2,59)^{2}+(0)^{2}+(29,71)^{2}} \\
& =35,37
\end{aligned}
$$

In the $2^{\text {nd }}$ iteration, the path's efficiency is lower than $1^{\text {st }}$ iteratio. The smoothing index value at $2^{\text {nd }}$ iteration is 33.90 . This indicates that the SI value is greater than $1^{\text {st }}$ iteration $(33.90>17.07)$, as well as the idle value of iteration 2 which is greater than iteration $1(48,43>33,03)$.

Each iteration yields a percent difference in track efficiency and balance delay, and the indicator values of the smoothing index are also different, as well as the number of idle times and different cycle times at each work center. So, its necessary for us to make a 
comparison of the three iterations to choose the best. Recapitulation of iterative comparison can be seen in Table 4 below.

Table 4. Comparative Results of Final Assembly Processes Iteration

\begin{tabular}{cccccc}
\hline Iteration & $\begin{array}{c}\text { Total } \\
\text { WC }\end{array}$ & $\begin{array}{c}\text { Efficiency } \\
(\%)\end{array}$ & $\begin{array}{c}\text { Balance } \\
\text { Delay (\%) }\end{array}$ & $\begin{array}{c}\text { Smoo- } \\
\text { thing } \\
\text { Index }\end{array}$ & $\begin{array}{c}\text { Idle } \\
\text { Time (s) }\end{array}$ \\
\hline 0 & 6 & 85,50 & 14,50 & 15,59 & 43,77 \\
1 & 5 & 88,65 & 11,35 & 17,07 & 33,03 \\
II & 4 & 84,20 & 15,80 & 33,90 & 48,43 \\
\hline
\end{tabular}

Reviewing from Table 4, the comparison of the above three iterations is based on the aspect of efficiency value, balance delay, smoothing index, and idle time, the best iteration chosen is $1^{\text {st }}$ iteration. Illustration of balance condition of $1^{\text {st }}$ Iteration can be seen in Figure 3.

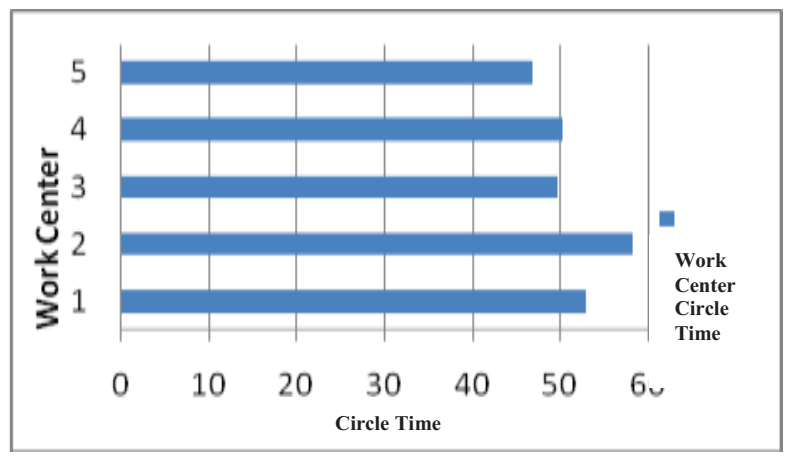

Figure 3. Track Balance Condition with 1st Iteration

The final assembly trajectory in Figure 3 is the result of the solution splitting using TOC. Can be seen the cycle time of each work center does not differ too much (balanced) compared with actual conditions. It can also be seen from the smoothing index value of the selected solution ie $1^{\text {st }}$ iteration which is smaller than the actual condition.

In the processing steps of theory of constraints has been done identification constraints that occur in the company by using tools current reality tree. The results of identification indicate the existence of bottleneck in some work center that is WC 5 and WC 6 because of the cycle time between different operators far. Illustration of trajectory of the actual final assembly process can be seen in Figure 4. 


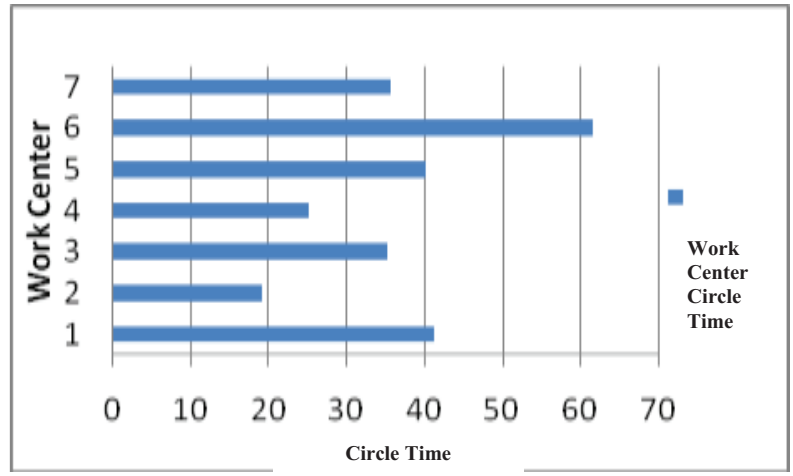

Figure 4. Actual Trajectory Condition of Final Assembly Process

The actual trajectory condition shows in Figure 4, can be seen that the path with 7 work centers has an efficiency that is $59.80 \%$, balance delay is $40.20 \%$, and smoothing index is 73.47. These values indicate the need for track balancing, so that the Theory of Constraints (TOC) principle is used.

To determine the best method between the actual condition and after the improvement design analysis by using performance parameters to be applied to the company. Comparison of result of balancing parameter of production line used is efficiency index (EI). The TOC method shows that the conditions in Iteration I are better than the actual condition with the increase of efficiency as follows:

$$
(\mathrm{IE})=\frac{E \text { (TOC) }}{\mathbf{E} \text { (Actual) }}=\frac{88,65}{59,80}=1,48
$$

An efficiency index of 1.48 indicates that the final assembly path with TOC method is better than the actual condition so that the company can apply the proposed trajectory design to obtain the optimum production trajectory.

The number of actual work centers is 7 and after balancing the TOC method, the number of work centers is 5 . The result will not interfere with the production process due to the increased efficiency, balance delay down, and smoothing index down compared to the actual condition.

\section{Conclusions}

The conclusions of the observation and data processing are as follows:

1. The final assembly process has a bottleneck on WC 6 .

2. Implementation of constraints theory allocates 21 elements of actual work with 7 work centers into 5 work centers.

3. Production path with TOC heuristic approach method produces efficiency about $88,65 \%$, balance delay $11,35 \%$, and smoothing index 17,07 .

4. Efficiency index of TOC usage increased by 1.48 compared to actual condition.

\section{References}

1. Dalle Mura, M., \& Dini, G. (2016). Worker Skills and Equipment Optimization in Assembly Line Balancing by a Genetic Approach. Procedia CIRP, 44, 102-107. 
2. Oesterle, J., Bauernhansl, T., \& Amodeo, L. (2016). Hybrid Multi-objective Optimization Method for Solving Simultaneously the line Balancing, Equipment and Buffer Sizing Problems for Hybrid Assembly Systems. Procedia CIRP, 57, 416-421.

3. Borreguero, T., Mas, F., Menéndez, J. L., \& Barreda, M. A. (2015). Enhanced Assembly Line Balancing and Scheduling Methodology for the Aeronautical Industry. Procedia Engineering, 132, 990-997.

4. Pröpster, M., März, L., Reinhart, G., \& Intra, C. (2015). Validation of Line Balancing by Simulation of Workforce Flexibility. Procedia CIRP, 33, 93-98.

5. Borba, L., \& Ritt, M. (2014). A heuristic and a branch-and-bound algorithm for the Assembly Line Worker Assignment and Balancing Problem. Computers \& Operations Research, 45, 87-96.

6. Bentaha, M. L., Battaïa, O., \& Dolgui, A. (2014). Disassembly line balancing and sequencing under uncertainty. Procedia CIRP, 15, 239-244.

7. Aguilar-Escobar, V. G., \& Garrido-Vega, P. (2016). Applying the theory of constraints to the logistics service of medical records of a hospital. European Research on Management and Business Economics, 22(3), 139-146.

8. Izmailov, A., Korneva, D., \& Kozhemiakin, A. (2016). Effective Project Management with Theory of Constraints. Procedia-Social and Behavioral Sciences, 229, 96-103.

9. Okutmuş, E., Kahveci, A., \& Kartašova, J. (2015). Using theory of constraints for reaching optimal product mix: an application in the furniture sector. Intellectual Economics, 9(2), 138-149.

10. Siregar, I., Suantio, H., Hanifiah, Y., Muchtar, M. A., \& Nasution, T. H. (2017, January). Fuzzy linear programming for bulb production. In Journal of Physics: Conference Series (Vol. 801, No. 1, p. 012001). IOP Publishing.

11. Siregar, B., Butar-Butar, I. A., Rahmat, R. F., Andayani, U., \& Fahmi, F. (2017, January). Comparison of Exponential Smoothing Methods in Forecasting Palm Oil Real Production. In Journal of Physics: Conference Series (Vol. 801, No. 1, p. 012004). IOP Publishing. 